\title{
Development of resistance during ceftazidime and cefepime therapy in a murine peritonitis model
}

\author{
Jean-Claude Pechère and Ion Rusan Vladoianu \\ Departement de Génétique et Microbiologie, Centre Médical Universitaire, 9 av. de \\ Champel CH-1211 Geneva, Switzerland
}

\begin{abstract}
Resistance emerging after ceftazidime or cefepime therapy was investigated in a peritonitis model. Mice were given a peritoneal challenge ( $10^{3} \mathrm{cfu}$ plus talcum) and treated by either antibiotic $(50 \mathrm{mg} / \mathrm{kg} /$ dose, which produced similar antibiotic concentrations in peritoneal fluid in both cases). After one or three doses, resistance never developed in Serratia marcescens or Citrobacter freundii infections. After Enterabacter cloacae and Pseudamonas aeruginasa challenge, ceftazidime selected more resistance (21/36 cases) than did cefepime ( $1 / 36$ cases). In mice challenged with resistant strains selected by ceftazidime therapy, cefepime (six doses) successfully treated $7 / 18 \mathrm{E}$. cloacae infections but $0 / 18 \boldsymbol{P}$. aeruginosa infections; ceftazidime was never effective. Neither cefepime nor ceftazidime cured mice infected with the resistant strain selected by cefepime. MICs were poor predictors of further emergence of resistance in mice inoculated with strains classified as susceptible, but antibiotic-containing agar gradients plated with a high inoculum $\left(10^{4} \mathrm{cfu}\right)$ allowed better prediction. In selected clinical situations, cefepime may be preferable because it may be associated with less frequent emergence of resistance.
\end{abstract}

\section{Introduction}

Development of bacterial resistance during a therapy with third generation cephalosporins such as cefotaxime and ceftazidime has been repeatedly documented (Pechere, 1989 ) and is of concern in hospital practice. It is a particular problem in infections caused by Enterobacter cloacae or Pseudomonas aeruginosa (King et al., 1983; Quinn, Di Vicenzo \& Foster, 1987). Recently, other cephalosporins have been developed, aimed at limiting this problem. Cefepime is one of these recent $\beta$-lactam drugs, showing poor affinities for $\beta$-lactamases combined with stability to enzymatic hydrolysis (Phelps et al., 1986; Hiraoka et al., 1988; Bellido, Pechère \& Hancock, 1991) and maintaining in-vitro activity against ceftazidime and cefotaxime resistant strains belonging to the genera Enterobacter, Pseudomonas and Citrobacter (Vuye \& Pick, 1985; Fung-Tome et al., 1989).

In order to evaluate the risk of resistance arising during antibiotic therapy, a murine model has been developed (Pechère et al., 1986; Marchou et al., 1987b). In this model, emergence of resistance depended on the bacterial species inoculated in the animal and on the compound administered. Resistance was seen more often with $E$. cloacae followed by $P$. aeruginosa and Serratia marcescens. A greater risk of resistance was associated with therapy by third generation cephalosporins (cefotaxime, ceftriaxone, 
ceftazidime) followed by monobactams (carumonam, aztreonam), while resistance during imipenem therapy was uncommon and limited to $P$. aeruginosa. With a similar model, we have examined the phenomenon of resistance acquired during therapy with cefepime in comparison with ceftazidime, as well as the relevant virulence capabilities of resistant strains obtained in the model.

\section{Methods}

\section{Bacteria}

The bacterial strains used in this study were clinical isolates. $E$. cloacae $218 \mathrm{~S}$ and $219 \mathrm{~S}$ were isolated from cerebrospinal fluid in patients with purulent meningitis (Eng et al., 1987). S. marcescens 239 and $240, C$. freundii 151 and 158 were strains isolated in blood cultures from patients not treated with $\beta$-lactam agents before the blood sampling. $P$. aeruginosa $302 S$ and $305 S$ were isolated from infected wounds (Michea-Hamzehpour et al., 1987).

\section{Antibiotics}

Cefepime, (sulphate salt), was provided by Bristol-Myers-Squibb, Syracuse, NY, USA; ceftazidime was obtained from Glaxo AG, Bern, Switzerland. Working solutions were freshly prepared from powders of known potency according to the recommendations of the manufacturer.

\section{Growth-inhibitory activity}

MICs were determined by two methods. The first was an agar dilution method (National Committee for Clinical Laboratory Standards, 1985). The inoculum contained $c .10^{4}$ cfu per spot. The second method used antibiotic gradient containing plates, as described previously (Marchou et al., 1987a). The inoculum was c. 10 per dish. This method allowed the definition of two levels of antibiotic activity. The first level was read as the boundary concentration, the boundary being the relatively sharp limit separating the confluent growth at lower antibiotic concentrations from the zone of higher antibiotic concentrations, where only single colonies grew. The second level of antibiotic activity, called no-growth concentration, was the minimal concentration inhibiting all visible growth.

\section{Antibiotic resistance acquired in vivo}

Swiss ICR female mice, weighing $20-30 \mathrm{~g}$, were conditioned for one week after receipt from the breeder and kept in conventional cages with free access to water and antibiotic-free chow. Inoculum was prepared from an overnight broth culture and diluted with $0.9 \% \mathrm{NaCl}$. One $\mathrm{mL}$ of the diluted culture, containing approximately $10^{3} \mathrm{cfu}$, and $125 \mathrm{mg}$ of sterile talcum (magnesium hydropolysilicate), was injected intraperitoneally to establish peritonitis. Talcum was used as a foreign body in order to ascertain lethal sepsis in all cases. Two hours after bacterial challenge the antibiotic therapy started, with the administration of subcutaneous doses of $50 \mathrm{mg} / \mathrm{kg}$ of cefepime or ceftazidime. Three therapeutic schedules were used: single dose, three doses (dosing intervals: $\mathbf{2 h}$ ) or six doses (dosing intervals: $\mathbf{2 h}$ ). Analysis of the peritoneal 
bacterial population was performed by sampling the peritoneal fluid at various time intervals with a syringe and needle. Mice were killed by cervical dislocation $24 \mathrm{~h}$ after inoculation. The peritoneal fluid was plated after appropriate dilutions on antibioticfree agar for colony counts, whereas the rest of the sample was placed into antibioticfree broth to allow overnight growth for further susceptibility testing. Data were compared from treated and untreated control animals. At autopsy, heart blood and spleen pulp were sampled for viable counts after careful local heat-searing of the organ surface, followed by collection with syringe and needle. A significant shift to resistance was defined as an increase of the boundary concentration by at least four-fold.

\section{Antibiotic assays}

Mice were injected intraperitoneally with $1 \mathrm{~mL}$ of $0.9 \% \mathrm{NaCl}$, containing $250 \mathrm{mg}$ of sterile talcum. Two hours later, antibiotics were administered subcutaneously, $50 \mathrm{mg} / \mathrm{kg}$. Mice were killed by cervical dislocation (three or four animals per time interval), peritoneal exudate was sampled and deposited on $6.5 \mathrm{~mm}$ paper discs. Assays were performed by using a disc-diffusion method, with Mueller-Hinton agar and Staphylococcus aureus as the test organism.

\section{Virulence assay}

Using groups of five mice over an inoculum range of approximately $10^{1}$ to $10^{9} \mathrm{cfu}$ (i.e. 25-30 animals for each strain studied), the virulence of initial and post-therapy strains injected intraperitoneally was estimated after determination of the inoculum able to kill $50 \%$ of the animals inoculated $\left(\mathrm{LD}_{\mathrm{sa}}\right)$.

\section{Results}

\section{Susceptibility testing before therapy}

Before therapeutic exposure, the eight strains used in the study were susceptible to both cefepime and ceftazidime (Table I). As judged by MICs in agar dilution, and on a weight basis, cefepime was more potent than ceftazidime against $E$. cloacae, $S$. marcescens and Citrobacter freundii, but ceftazidime was more active against $P$. aeruginosa. MICs, as measured by agar dilution, were very similar to the boundary concentrations as determined on antibiotic-containing agar. On gradient plates, nogrowth concentrations were in the same range (a difference of four-fold or less) as the corresponding boundary concentration for both cefepime and ceftazidime in $S$. marcescens and $C$. freundii, and for cefepime only in $E$. cloacae and $P$. aeruginosa. In the two latter species, no-growth concentrations were higher than boundary concentrations by ten- to 150-fold when ceftazidime was tested, and overall, no-growth concentrations were higher for ceftazidime than for cefepime.

\section{Antibiotic assays}

Ceftazidime and cefepime displayed similar pharmacokinetic profiles in the peritoneal fluid, with antibiotic concentrations far above the MICs of initial strains 60 and $120 \mathrm{~min}$ after a $50 \mathrm{mg} / \mathrm{kg}$ dosing (Table II). 
Table I. Growth inhibitory activity of cefepime and ceftazidime before therapeutic exposure

\begin{tabular}{|c|c|c|c|c|}
\hline \multirow[b]{2}{*}{ Strain } & \multirow[b]{2}{*}{ Antibiotic } & \multicolumn{3}{|c|}{ Growth inhibitory concentrations ( $\mathrm{mg} / \mathrm{L}$ ) } \\
\hline & & MIC & boundary & no-growth \\
\hline \multirow[t]{2}{*}{ E. cloacae $218 \mathrm{~S}$} & cefepime & $0-06$ & $0-04$ & 0.125 \\
\hline & ceftazidime & 0.25 & $0-24$ & 20 \\
\hline \multirow[t]{2}{*}{ E. cloacae $219 \mathrm{~S}$} & cefepime & $0-06$ & $0-04$ & $0-20$ \\
\hline & ceftazidime & $0-25$ & $0-20$ & 32 \\
\hline \multirow[t]{2}{*}{$S$. marcescens 239} & cefepime & 1.6 & 1.5 & $2 \cdot 5$ \\
\hline & ceftazidime & 4 & 30 & 6 \\
\hline \multirow[t]{2}{*}{ S. marcescens 240} & cefepime & $0-06$ & $0-05$ & 0.15 \\
\hline & ceftazidime & 0.12 & $0-12$ & 1 \\
\hline \multirow[t]{2}{*}{ C. freundii 151} & cefepime & $0-06$ & $0-03$ & $0-08$ \\
\hline & ceftazidime & $0-4$ & 0.3 & $0-5$ \\
\hline \multirow[t]{2}{*}{ C. freundii 158} & cefepime & $0-06$ & $0-03$ & $0-06$ \\
\hline & ceftazidime & 0.25 & 0.24 & 0.5 \\
\hline \multirow[t]{2}{*}{$P$. aeruginosa $302 S$} & cefepime & 1 & $2 \cdot 5$ & 5 \\
\hline & ceftazidime & $0-5$ & 1.5 & 30 \\
\hline \multirow{2}{*}{ P.aeruginosa 305S } & cefepime & 2 & 6 & 6 \\
\hline & ceftazidime & 2 & $1 \cdot 5$ & 15 \\
\hline
\end{tabular}

"As measured by agar dilution (inoculum: c. $10^{4}$ cfu per spot); "as measured on antibiotic gradient contajning agar (inoculum: c. $10^{4}$ cfu per dish).

\section{Emergence of resistance after a first therapeutic exposure}

Thirty-two untreated mice, serving as controls (four per strain) were killed and autopsied $24 \mathrm{~h}$ after inoculation challenge. Severe peritonitis was observed in all cases, and the peritoneal fluid contained from $9.1 \times 10^{9}$ to $7 \times 10^{10} \mathrm{cfu} / \mathrm{mL}$ (all bacterial strains being considered), when the inoculum used for challenging the animals was $1.6 \pm 3.5 \times 10^{3} \mathrm{cfu} / \mathrm{mL}$. Autopsy of control mice also showed enlarged spleens which yielded growth of the pathogen inoculated in all cases. Blood cultures were positive in $90 \%$ of the cases. One hundred and forty-four mice were treated by cefepime or ceftazidime, one or three doses of $50 \mathrm{mg} / \mathrm{kg}$ each (Table III). Resistance did not develop in any mouse infected with $S$. marcescens or $C$. freundii. In mice infected with $E$. cloacae or $P$. aeruginosa, resistance commonly occurred after ceftazidime therapy with either the one or three dose regimens; with cefepime resistance developed in only a

Table II. Antibiotic concentration in peritoneal fluid after subcutaneous administration of cefepime or ceftazidime in mice with aseptic peritonitis

\begin{tabular}{lcc}
\hline $\begin{array}{l}\text { Antibiotic administered } \\
\text { (dosing) }\end{array}$ & $\begin{array}{c}\text { Time (min) } \\
\text { after dosing }\end{array}$ & $\begin{array}{c}\text { Antibiotic concentration (mgL) } \\
\text { in peritoneal fluid }\end{array}$ \\
\hline Ceftazidime & 30 & 64.6 \\
$(50 \mathrm{mg} / \mathrm{kg})$ & 60 & $57 \cdot 8$ \\
& 120 & $13 \cdot 0$ \\
Cefepime & 180 & $<2 \cdot 5$ \\
$(50 \mathrm{mg} / \mathrm{kg})$ & 60 & 38.2 \\
& 120 & $12 \cdot 9$ \\
& 180 & $3 \cdot 3$ \\
\hline
\end{tabular}

Mean of three or four mice. 
Table III. Resistance emerging after therapy with cefepime or ceftaxidime, one or three doses $(50 \mathrm{mg} / \mathrm{kg})$

\begin{tabular}{|c|c|c|c|}
\hline Strain & Therapy & $\begin{array}{l}\text { Number of mice } \\
\text { (fold increase of } \\
\text { after one dose }\end{array}$ & $\begin{array}{l}\text { acquired resistance } \\
\text { lary concentration) } \\
\text { After three doses }\end{array}$ \\
\hline E. cloacae 218 & cefepime & 0 & 0 \\
\hline E. claacae 219 & cefepime & $\begin{array}{l}3(125-200) \\
0\end{array}$ & $1(50)$ \\
\hline S. marcescens 239 & cefepime & $l_{0}(250-040)$ & 0 \\
\hline S. marcescens 240 & cefepime & $\begin{array}{l}0 \\
0\end{array}$ & $\begin{array}{l}0 \\
0\end{array}$ \\
\hline C. freundii 151 & $\begin{array}{l}\text { cefepime } \\
\text { ceftazidime }\end{array}$ & $\begin{array}{l}0 \\
0\end{array}$ & $\begin{array}{l}0 \\
0\end{array}$ \\
\hline C. freundii 158 & cefepime & $\begin{array}{l}0 \\
0\end{array}$ & $\begin{array}{l}0 \\
0\end{array}$ \\
\hline P. aeruginosa 302 & $\begin{array}{l}\text { cefepime } \\
\text { ceftazidime }\end{array}$ & $\begin{array}{l}0 \\
2(8)\end{array}$ & $\begin{array}{l}0 \\
2(20)\end{array}$ \\
\hline P. aeruginasa 305 & $\begin{array}{l}\text { cefepime } \\
\text { ceftazidime }\end{array}$ & $\begin{array}{l}0 \\
2(8)\end{array}$ & $0_{1(17}$ \\
\hline
\end{tabular}

Out of six mice inoculated.

Dut of three mice inoculated.

single mouse infected with E. cloacae 219S and dosed three times (Table IIn). Chi-square statistics, after Yates' correction, indicated that in $E$. cloacae infected mice receiving a single antibiotic dose, resistance was significantly more frequent after ceftazidime than after cefepime therapy $(P<0-01)$. When resistance emerged, MIC increases were impressive (at least 80-fold) in E. cloacae infections, and more limited (eight-fold) in $P$. aeruginosa infections. As to the peritoneal viable counts, an antibiotic effect was observed in all cases, i.e. a decrease of at least two logs compared to parallel counts in the corresponding untreated mice. Twenty-four hours after challenge, treated animals had 2.3 to over 6 logs lower counts than did untreated animals, even when resistance occurred. For four of the strains under study, peritoneal viable counts were determined over $24 \mathrm{~h}$ in animals receiving three antibiotic doses or no antibiotic (controls) (Figure 1). Within the first $8 \mathrm{~h}$ following bacterial challenge, these counts were indistinguishable whether cefepime or ceftazidime was administered; after $24 \mathrm{~b}$, viable counts remained similar in three experiments, while cefepime therapy was associated with a lower peritoneal cfu count in E. cloacae 2195 (Figure 1) where resistance emerged after ceftazidime therapy.

\section{Prediction of emergence of resistance in vitro}

The eight strains exposed to cefepime or ceftazidime therapy were initially classified as susceptible to these antibiotics according to standard MIC determination, but resistance emerged in some of the animals treated. So we tried to find other in-vitro parameters which would be able to ensure a better prediction of the therapeutic outcome in the model. Higher no-growth concentration on antibiotic-containing gradient agar was associated with greater risk of resistance in vivo, except in the 


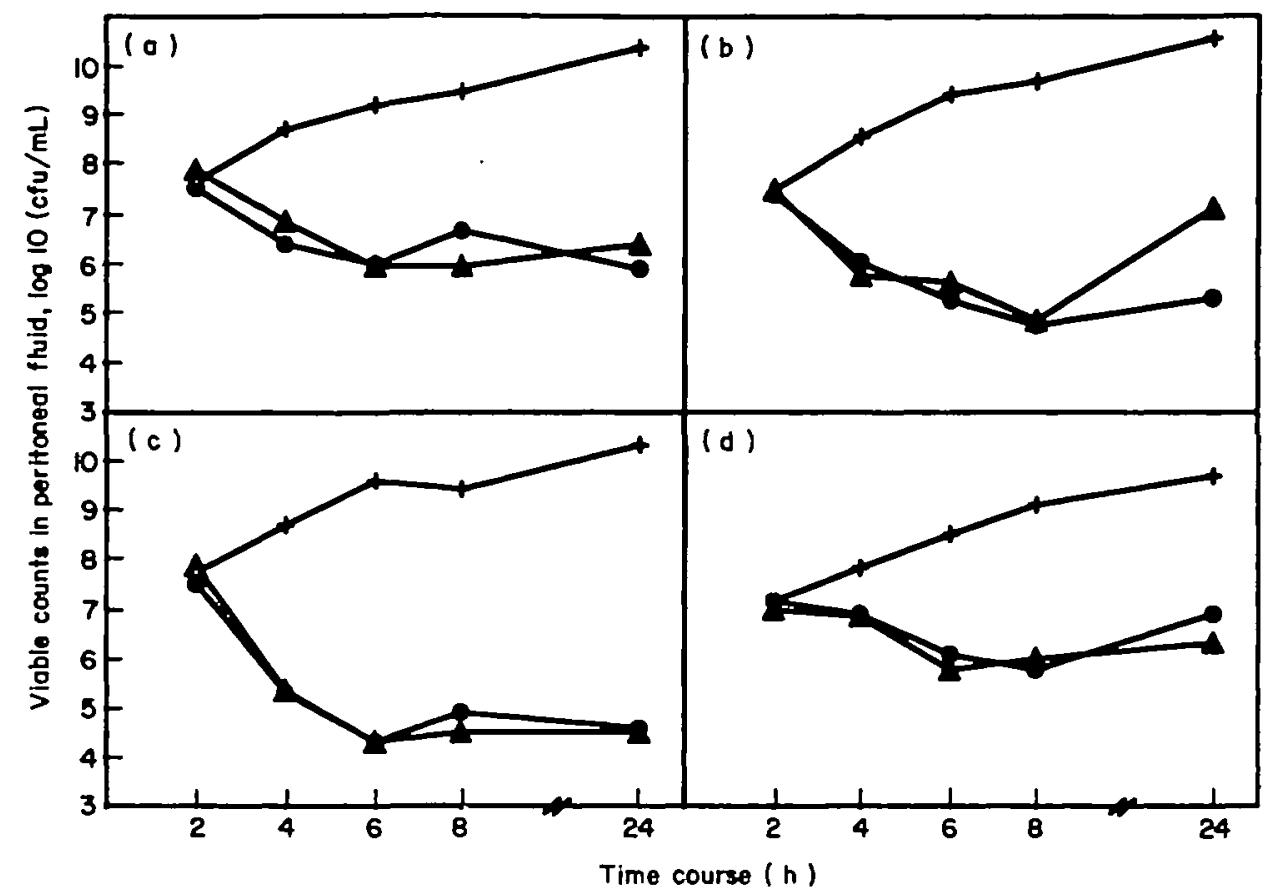

Fhore 1. Viable counts of peritoneal bacteria in treated and untreated control mice after peritoneal challenge with $10^{\prime}$ cfu. (a) $E$. cloacae $218 S$; (b) E. claacae 219S; (c) C. freundii 151; (d) P. aeniginasa $302 S$. + , No treatment; $\Delta$, ceftazidime;, , cefepime.

cefepime-treated mouse infected with $E$. cloacae $219 S$ where resistance emerged (Table In) despite low no-growth concentration (Table I). A greater correlation was found with the ratio of no-growth concentration to the boundary concentration versus the number of mice in which resistance developed (Figure 2).

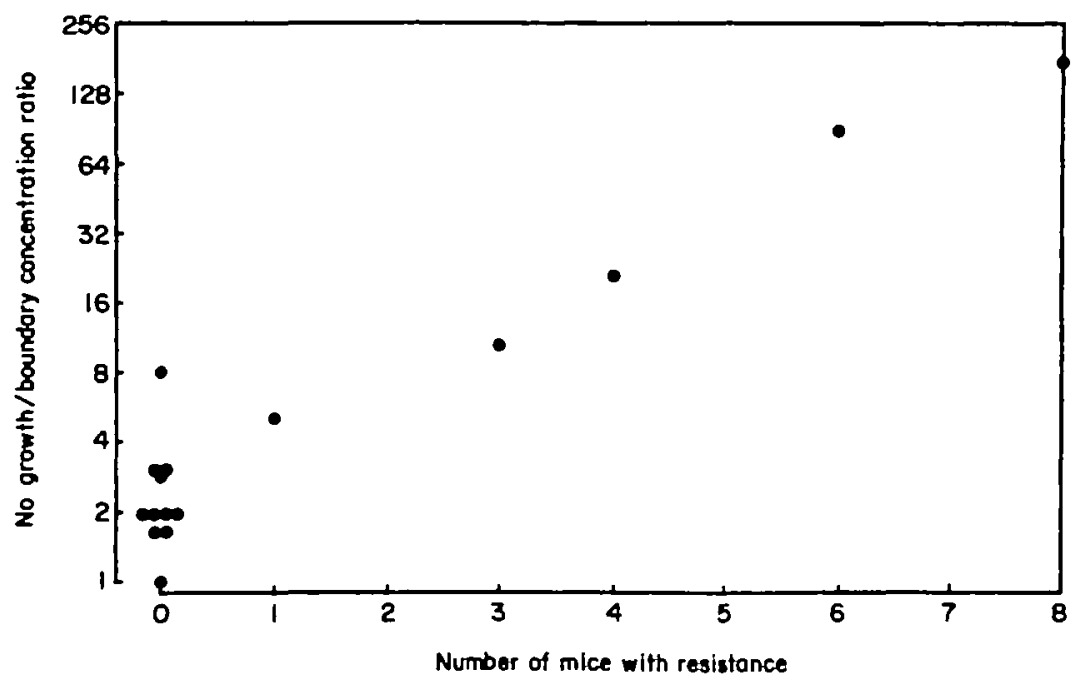

Figare 2 Correlation of emergence of resistance in mice with resistance as judged by cefepime- or ceftazidime-gradient containing agar. 
Table IV. Growth inhibitory activity of cefepime and ceftazidime against resistant isolates selected in vivo

\begin{tabular}{llcc}
\hline Strain & Antibiotic & $\begin{array}{c}\text { Growth inhibitory concentrations (mg/L) } \\
\text { MIC }\end{array}$ & $\begin{array}{c}\text { coundary } \\
\text { bour }\end{array}$ \\
\hline 218 R (CTZ) & cefepime & 0.5 & 4 \\
& ceftazidime & 32 & 50 \\
$219 \mathrm{R}(\mathrm{CTZ})$ & cefepime & 4 & 256 \\
& ceftazidime & $>128$ & 256 \\
$219 \mathrm{R}(\mathrm{CPM})$ & cefepime & 2 & 128 \\
& ceftazidime & 128 & 128 \\
$302 \mathrm{R}(\mathrm{CTZ})$ & cefepime & 8 & 128 \\
& ceftazidime & 32 & 128 \\
$305 \mathrm{R}(\mathrm{CTZ})$ & cefepime & 32 & 128 \\
& ceftazidime & 128 & 128 \\
\hline
\end{tabular}

-As measured by agar dilution (inoculum: $c$. $10^{4}$ cfu per spot).

As measured by antibiotic gradient containing agar (inoculum: c. $10^{2}$ cfu per dish).

\section{Second therapeutic exposure}

From each group of mice in which resistance emerged during therapy, one or two resistant isolates were chosen randomly for further studies. Five strains originated from ceftazidime-treated mice (respectively $218 \mathrm{R}$ (CTZ) 1 and 2, $219 \mathrm{R}$ (CTZ), $302 \mathrm{R}$ (CTZ) and $305 \mathrm{R}$ (CTZ)). A sixth strain came from the only cefepime-treated mouse showing bacterial resistance (219 R (CPM)). Growth inhibitory activity of cefepime and ceftazidime in vitro against these strains is summarized in Table IV. According to the agar dilution method with a $10^{4} \mathrm{cfu}$ inoculum, MICs of cefepime always remained lower than those of ceftazidime, by four-fold against $P$. aeruginosa and by at least 64 fold against $E$. cloacae. With the antibiotic containing gradient agar however, using a $10^{3} \mathrm{cfu}$ inoculum, boundary concentrations increased markedly, becoming similar for the two antibiotics.

In order to evaluate the therapeutic impact of these diminished in-vitro activities, the six resistant isolates were inoculated into naive mice, according the same protocol. Ten untreated mice were used as controls for these experiments, and killed $24 \mathrm{~h}$ after challenge. The macroscopic appearance of peritoneal cavities, and viable counts in the peritoneal fluid were similar to those found in untreated mice inoculated with cephalosporin-susceptible parent strains. This was a first indication that the resistant isolates had kept at least part of their initial virulence. Forty-eight mice were inoculated with one of the resistant isolates and treated with six antibiotic doses. The peritoneal cavity was sampled one day after challenge to confirm establishment of infection. All peritoneal fluids yielded growth of the species inoculated. Nine ceftazidime-treated mice had a peritoneal bacterial population which was more resistant to ceftazidime by two- to eight-fold, compared to the organism inoculated, (strains $218 \mathrm{R}$ (CTZ) 1 and 302 R (CTZ)). All ceftazidime-treated animals were dead by day 3, and most of them by day 2 after challenge (Table $V$ ). After 30 days of observation, cefepime ensured survival for the six mice infected with $219 \mathrm{R}$ (CTZ), and one out of 12 mice infected with $218 \mathrm{R}$ (CTZ), but no protection against infections produced by $219 \mathrm{R}$ (CPM) or the pseudomonas isolates. For comparison purposes, 24 mice were inoculated with E. cloacae $218 \mathrm{~S}$ and $219 \mathrm{~S}$ (susceptible to cephalosporins) and treated as above 
Table V. Therapeutic effects on survival of mice challenged with resistant isolates and treated by cefepime or ceftazidime (six doses, $50 \mathrm{mg} / \mathrm{kg}$ each, $2 \mathrm{~h}$ apart)

\begin{tabular}{|c|c|c|c|c|c|}
\hline \multirow[b]{2}{*}{ Strain } & \multirow[b]{2}{*}{ Therapy } & \multicolumn{4}{|c|}{ Number of mice } \\
\hline & & inoculated & 2 & 3 & 30 \\
\hline \multirow[t]{2}{*}{$218 \mathrm{~S}$} & cefepime & 6 & 6 & 6 & 6 \\
\hline & ceftazidime & 6 & 5 & 3 & 3 \\
\hline \multirow[t]{2}{*}{$219 S$} & cefepime & 6 & 6 & 6 & 6 \\
\hline & ceftazidime & 6 & 4 & 0 & 0 \\
\hline \multirow[t]{2}{*}{$218 \mathrm{R}(\mathrm{CTZ})$} & cefepime & 12 & 3 & 1 & 1 \\
\hline & ceftazidime & 6 & 0 & 0 & 0 \\
\hline \multirow[t]{2}{*}{$219 \mathrm{R}$ (CTZ) } & cefepime & 6 & 6 & 6 & 6 \\
\hline & ceftazidime & 6 & 5 & 0 & $\mathbf{0}$ \\
\hline \multirow[t]{2}{*}{219 R (CPM) } & cefepime & 3 & 0 & 0 & 0 \\
\hline & ceftazidime & 3 & 0 & 0 & 0 \\
\hline \multirow[t]{2}{*}{$302 \mathrm{R}$ (CTZ) } & cefepime & 3 & 0 & 0 & 0 \\
\hline & ceftazidime & 3 & 0 & 0 & 0 \\
\hline \multirow[t]{2}{*}{$305 \mathrm{R}(\mathrm{CTZ})$} & cefepime & 3 & 0 & 0 & 0 \\
\hline & ceftazidime & 3 & 0 & 0 & 0 \\
\hline
\end{tabular}

(Table V). One month after challenge, the 12 cefepime-treated animals survived, compared to three out of the 12 mice which were given ceftazidime $(P<005)$.

Overall, the 22 mice still alive one month after challenge ( $E$. cloacae in all cases) were apparently healthy. However, at autopsy we found small peritoneal abcesses and adhesions in seven of them (one ceftazidime-treated, six cefepime treated). Culture of the pus yielded $E$. cloacae, with the same pattern of antibiotic activities as the strain inoculated.

\section{Virulence studies}

The $\mathrm{LD}_{s 0}$ of each pair of pre-and post therapy (resistant) strains were less than five-fold different in all cases, except for the 302 pair, which was approximately one log

Table VI. Virulence of parent strains and cephalosporin-resistant mutants of $E$. cloacae and $P$. aeruginosa

\begin{tabular}{ll}
\hline Strain & $\mathrm{LD}_{\text {so }}$ (cfu) \\
\hline$E$. cloacae 218S & $95 \times 10^{6}$ \\
E. cloacae 219S & $1.8 \times 10^{6}$ \\
$E$. cloacae 218 R (CTZ)1 & $2.0 \times 10^{6}$ \\
$E$. cloacae 218 R (CTZ)2 & $4.9 \times 10^{6}$ \\
$E$. cloacae 219 R (CTZ) & $2.9 \times 10^{6}$ \\
$E$. cloacae 219 R (CPM) & $1.0 \times 10^{6}$ \\
$P$. aeruginasa 302S & $2.7 \times 10^{4}$ \\
$P$. aeruginosa 305S & $1.0 \times 10^{3}$ \\
$P$. aeruginosa 302 R (CTZ) & $1.9 \times 10^{3}$ \\
$P$. aenuginosa 305 R (CTZ) & $2.5 \times 10^{3}$ \\
\hline
\end{tabular}


different. No consistent trend towards an increase or decrease in virulence was noted after occurrence of resistance (Table VI).

\section{Discussion}

After therapy of $P$. aeruginosa and $E$. cloacae infections, cefepime produced signifcantly less emergence of resistance than did ceftazidime, and cefepime therapy occasionally remained efficient in treating mice infected with resistant $E$. cloacae selected by ceftazidime. Several factors could account for this 'dissociated resistance' in vivo. Host factors were not investigated, and antibiotic concentrations in peritoneal fluid were similar for the two drugs under study. However differences exist at the bacterial level. Resistance emerging during $\beta$-lactam therapy of infections caused by aerobic non-fastidious Gram-negative bacilli is thought to result from the selection of low frequency mutants characterized by high $\beta$-lactamase production, decreased outer membrane permeability or both (Marchou et al., 1987a; Sawai, Yamaguchi \& Hiruma, 1988). On antibiotic-gradient containing agars these mutants grew as single colonies well over the boundary concentration on ceftazidime, but not on cefepime gradients, in accordance with previous observations demonstrating the cefepime activity against ceftazidime-resistant bacteria (Vuye \& Pick, 1985; Fung-Tomc et al., 1989). Recent studies conducted with $E$. cloacae 218 (Bellido et al., 1991) showed that the $V_{\operatorname{man}}$, reflecting the stability of $\beta$-lactamase-substrate complex, was in the same range for cefepime and 'conventional' third generation cephalosporins; by contrast, the $K_{m}$ value for cefepime was remarkably high, reflecting the previously described low affinity for the $\beta$-lactamase (Hiraoka et al., 1988). In addition, and again in comparison with older cephalosporins, cefepime was shown to cross the outer membrane more rapidly and this was so even in a porin F-deficient mutant of $E$. cloacae 218 (Bellido et al., 1991). Altogether, in a given time, more cefepime molecules penetrate into the periplasmic space, avoid the $\beta$-lactamase attack and get access to the target molecules, for which cefepime does not show improved affinity (Bellido et al., 1991).

We have attempted to address the difficult question of the significance of the resistance emerging during therapy. Clinically, this resistance is associated with therapeutic failure in about half of the cases (Milatovic \& Braveny, 1987). The time course of viable counts in peritoneal fluid from animals treated by either antibiotic showed that, whether or not resistance occurred, the bacterial populations remained similar, at least for the first $8 \mathrm{~h}$. A rather dramatic antibacterial effect was seen in all cases, which may correspond to the elimination of the susceptible population. The resistant mutants, which form a small minority within this population, grew at the same rate as their susceptible counterparts in broth medium (data not shown). So we assume that during the first hours following initiation of therapy, the lack of visible resistant cells in viable counts was due to their small number at the time of challenge. As an example, if the frequency of resistant cells was one in a million, a challenge inoculum of $10^{3} \mathrm{cfu}$ would have provided only 100 resistant cells. So resistance is not necessarily synonymous with therapeutic failure probably because, in some cases, the host defence can eliminate such small number of bacteria. However, despite the important structural and functional changes associated with the mutation to resistance (derepressed $\beta$-lactamase production, which represents a significant expense of energy, and altered permeability with possible consequences on bacterial uptake of various substances) the resistant mutants kept their initial virulence as determined here by the $\mathrm{LD}_{\mathbf{s 0}}$ assays. They also resisted 
treatment with their selective agents in vivo, leading to lethal therapeutic failure. These observations contrast with other examples where antibiotic resistance is associated with lower virulence such as gentamicin resistance in S. aureus (Musher et al., 1977; Pelletier, Richardson \& Feist, 1979) or P. aeruginosa (Keys \& Washington, 1977; Khakoo \& Kluge, 1978), isonazid resistance in Mycobacterium tuberculosis (Middlebrook, 1957) or antibiotic resistance in Neisseria gonorrhoeae (Stollerman, 1978).

Therapeutic failure occurring when the pathogen is classified as susceptible to the antibiotic administered in vitro represents a very major error of susceptibility testing which has been seen with recent broad spectrum $\beta$-lactam compounds used for treating non-fastidious Gram-negative aerobic bacteria like $E$. cloacae and $P$. aeruginosa (Sanders, 1984). In this setting, both animal and clinical studies (Michea-Hamzehpour et al., 1989) have shown that MICs (or their equivalent in disc diffusion techniques) were poor predictors of emergence of resistance, at least when the strains were 'socalled' susceptible. This is likely to be due to the bacterial inoculum used in the testing procedures (typically $10^{4}$ or $10^{5} \mathrm{cfu}$, and less in microtechniques) compared with the scarce number of mutants associated with resistance (often less than one in $10^{5}$ cells). Using a higher inoculum $\left(10^{3} \mathrm{cfu}\right)$, the antibiotic gradient method described here allowed detection of these mutants. Resistance occurred in the mice only when the difference in $\beta$-lactam inhibitory concentrations between the wild type cells and the mutants was at least five-fold, as determined by the ratio no-growth concentration/ boundary concentration. No resistance was observed when the two subpopulations were relatively similar (less than four-fold difference). By contrast, as shown previously (Michèa-Hamzehpour \& Pechère, 1989), the presence and frequency of resistant mutants, and even the level of their resistance in vitro to the $\beta$-lactam given to the animal, did not predict faithfully further development of resistance in vivo. The links which are likely to exist between these observations and pharmacokinetics obviously deserve further studies.

\section{Acknowledgements}

We thank R. E. Kessler and L. Lamb, from Bristol-Myers Squibb Pharmaceutical Research Institute USA for the determination of $L D_{50} \mathrm{~s}$, Mehri Michéa-Hamzehpour and Lasta Kocjancic for antibiotic assays, and Lasta Kocjancic for technical assistance in animal experiments. This work has been supported by Fonds National Suisse de la Recherche Scientifique (Grant 31-28007-89).

\section{References}

Bellido, F., Pechere, J. C. \& Hancock, R. E. W. (1991). Reevaluation of the factors involved in the efficacy of new $\beta$-lactams against Enterabacter cloacae. Antimicrobial Agents and Chemotherapy 35, 73-8.

Eng, R. H. K., Cherubin, C. E., Pechère, J. C. \& Beam, T. R. (1987). Treatment failures of cefotaxime and latamoxef in meningitis caused by Enterabacter and Serratia spp. Joumal of Antimicrobial Chemotherapy 20, 903-11,

Fung-Tomc, J., Dougherty, T. J., De Orio, F. J., Simich-Jacobson, V. \& Kessler, R. E. (1989). Activity of cefepime against ceftazidime- and cefotaxime-resistant Gram-negative bacteria and its relationship to $\beta$-lactamase levels. Antimicrobial Agents and Chemotherapy 33, 498-502. 
Hiraoka, M., Masuyoshi, S., Mitsuhashi, S., Tomatsu, K. \& Inoue, M. (1988). Cephalosporinase interactions and antimicrobial activity of BMY 28142, ceftazidime and cefotaxime. Jowmal of Antibiotics 41, 86-93.

Keys, T. F. \& Washington, J. A. (1977). II. Gentamicin-resistant Pseudomonas aeruginosa: Mayo Clinic experience, 1970-1976. Mayo Clinic Proceedings 52, 797-801.

Khakoo, R. A. \& Kluge, R. M. (1978). Decreased virulence of genetamicin-resistant strains of Pseudomonas aeruginosa in a rat model. Journal of Laboratory and Clinical Medicine 91, 96-103.

King, A., Shannon, K., Eykyn, S. \& Phillips, I. (1983). Reduced sensitivity to $\beta$-lactam antibiotics arising during ceftazidime treatment of Pseudomonas aeruginosa infections. Jownal of Antimicrobial Chemotherapy 12, 363-70.

Marchou, B., Bellido, F., Chamas, R., Lucain, C. \& Pechère, J. C. (1987a). Contribution of $\beta-$ lactamase hydrolysis and outer membrane permeability to ceftriaxone resistance in Enterobacter cloacae. Antimicrobial Agents and Chemotherapy 31, 1589-95.

Marchou, B., Michéa-Hamzehpour, M., Lucain, C. \& Pechère, J. C. (1987b). Development of $\beta$ lactam-resistant Enterobacter cloacae in mice. Joumal of Infectious Diseases 156, 369-73.

Michéa-Hamzehpour, M., Auckenthaler, R., Regamey, P. \& Pechère, J. C. (1987). Resistance occurring after fluoroquinolone therapy of experimental Pseudomonas aeruginosa peritonitis. Antimicrobial Agents and Chemotherapy 31, 1803-8.

Michéa-Hamzehpour, M. \& Pechère, J. C. (1989). How predictable is development of resistance after $\beta$-lactam therapy in Enterobacter cloacae infection? Journal of Antimicrobial Chemotherapy 24, 387-95.

Middlebrook, G. (1957). Diagnosis and biological problems of isoniazid-resistant tubercle bacilli. In Proceedings of the 14th International Tuberculosis Conference, New Delhi, pp. 71-97. Tuberculosis Association of India.

Milatovic, D. \& Braveny, I. (1987). Development of resistance during antibiotic therapy. European Journal of Clinical Microbiology 6, 234-44.

Musher, D. M., Baughn, R. E., Templeton, G. B. \& Minuth, J. N. (1977). Emergence of variant forms of Staphylococcus aureus after exposure to gentamicin infectivity of the variants in experimental animals. Journal of Infectious Diseases 136, 360-9.

National Committee for Clinical Laboratory Standards. (1985). Methods for Dilution Antimicrabial Susceptibility Tests for Bacteria that Grow Aerobically; Approved Standard M7-A. NCCLS, Villanova, PA.

Pechere, J. C. (1989). Emergence of resistance in Gram-negative bacilli during beta-lactam therapy: a challenge for the future. European Journal of Cancer and Clinical Oncology 25, Suppl. 2, S17-23.

Pechère, J. C., Marchou, B., Michèa-Hamzehpour, M. \& Auckenthaler, R. (1986). Emergence of resistance after therapy with antibiotics used alone or combined in a murine model. Journal of Antimicrobial Chemotherapy 17, Suppl. A, 11-8.

Pelletier, L. L., Richardson, M. \& Feist, M. (1979). Virulent gentamicin-induced small colony variants of Staphylococcus aureus. Journal of Laboratory and Clinical Medicine, 94, 324-34.

Phelps, D. J., Carlton, D. D., Farrell, C. A. \& Kessler, R. E. (1986). Affinity of cephalosporins for $\beta$-lactamases as a factor in antibacterial efficacy. Antimicrobial Agents and Chemotherapy 29, 845-8.

Quinn, J. P., DiVincenzo, C. A. \& Foster, J. (1987). Emergence of resistance to ceftazidime during therapy for Enterobacter cloacae infections. Journal of Infectious Diseases 155, 942-7.

Sanders, C. C. (1984). Failure to detect resistance in antimicrobial susceptibility tests. A "very major" error of increasing concern. Antimicrobic Newsletter 1, 27-31.

Sawai, T., Yamaguchi, A. \& Hiruma, R. (1988). Effect of interaction between outer membrane permeability and $\beta$-lactamase production on resistance to $\beta$-lactam agents in Gram-negative bacteria. Reviews of Infectious Diseases 10, 761-4.

Stollerman, G. H. (1978). Trends in bacterial virulence and antibiotic susceptibility: streptococci, pneumococci, and gonococci. Annals of Internal Medictne 89, 5 Pt 2 Suppl., 746-8.

Vuye, A. \& Pijck, J. (1985). In vitro antibacterial activity of BMY-28142, a new extendedspectrum cephalosporin. Antimicrobial Agents and Chemotherapy 27, 574-7.

(Received 14 October 1991; revised version accepted 22 January 1992) 
